\title{
PENINGKATAN PRODUKTIVITAS LAHAN KERING DI DESA GUMANTAR MELALUI BUDIDAYA IKAN SISTEM AKUAPONIK
}

\author{
Bagus Dwi Hari Setyono ${ }^{\left.1^{*}\right)}$, Muhammad Marzuki ${ }^{1)}$, Muhammad Junaidi ${ }^{2}$, Andre \\ Rachmat Scabra ${ }^{2)}$, Fariq Azhar ${ }^{2)}$ \\ 1)Program Studi Budidaya Perikanan, Program Vokasi Universitas Mataram (PDD) \\ Kabupaten Lombok Utara \\ 2)Program Studi Budidaya Perairan, Universitas Mataram \\ 1)Jalan Raya Kayangan-Tanjung, Kabupaten Lombok Utara \\ *alamat korespondensi: bagus.setyono@unram.ac.id
}

\begin{abstract}
ABSTRAK
Akuaponik merupakan perpaduan sistem budidaya antara hidroponik dengan akuakultur, sehingga menjadi suatu sistem produksi pangan terpadu. Dalam skala kecil, kombinasi produksi ikan dan sayur secara bersamaan menjadikan kemandirian kebutuhan nutrisi keluarga. Akuaponik dalam sistem akuakultur yang memanfaatkan limbah dari sisa pakan dan kotoran ikan sebagai pupuk pada tumbuhan hidroponik. Desa Gumantar, Kecamatan Kayangan, Kabupaten Lombok Utara merupakan bagian dari ekosistem terrestrial yang luasnya relatif lebih luas dibandingkan lahan basah. Ketersediaan air tawar menjadi faktor pembatas dalam aktivitas ekonomi dan keseharian masyarakat. Tujuan kegiatan pengabdian ini, diharapkan masyarakat mampu memanfaatkan lahan kering untuk budidaya perikanan. Kegiatan dimulai penentuan lokasi dan sistem akuaponik yang akan dipakai. Sistem akuaponik nutrient film technique adalah sistem yang cukup sederhana, yaitu memanfaatkan pipa-pipa yang sejajar dengan mengatur ketinggian outlet agar aliran air menjadi lancar. Sayur yang digunakan dalam sistem akuaponik adalah selada hijau, green pakcoy, bayam merah, bayam hijau, kangkung, dan caisim manis. Sedangkan ikan yang digunakan adalah ikan lele sebanyak 1.000 ekor yang diperoleh dari Balai Benih Ikan Batu Kumbung, Kabupaten Lombok Barat. Kegiatan ini menghasilkan produksi sayuran dan ikan lele pada satu masa pemeliharaan dengan nilai produksi yang cukup baik. Kesimpulan kegiatan pengabdian ini adalah masyarakat mampu memanfaatkan lahan kering untuk budidaya perikanan, melalui pemahaman konsep akuaponik yang baik dan menerapkannya melalui sistem nutrient film technique.
\end{abstract}

Kata kunci: akuaponik, ikan lele, sayuran 


\section{PENDAHULUAN}

Dusun Amor-Amor merupakan salah satu dusun di Desa Gumantar, Kecamatan Kayangan, Kabupaten Lombok Utara. Bentangan wilayah Dusun Amor-Amor dimulai dari dataran rendah (pantai) sampai dengan dataran tinggi (perbukitan). Sebagian besar wilayah Dusun AmorAmor berupa lahan kering, karena merupakan bagian dari ekosistem terrestrial yang luasnya relatif lebih luas dibandingkan lahan basah. Ketersediaan air tawar menjadi faktor pembatas dalam aktivitas ekonomi dan keseharian masyarakat. Hal tersebut ditambah lagi dengan kondisi tanah yang poros dan sangat mempengaruhi aktivitas masyarakat dalam bidang pertanian, peternakan, dan perikanan masyarakat Dusun Amor-Amor. Scabra et.al., (2016) menyatkaan bahwa air harus tersedia dalam jumlah yang cukup banyak untuk mendukung kegiatan akuakultur. Apabila ketersediaan air tidak dapat terpenuhi, maka diperlukan suatu penerapan teknologi budidaya ikan yang dapat memanfaatkan air dalam jumlah yang sedikit, namun tidak mengurangi efektifitas produksi yang dilakukan.

Peningkatan aktivitas ekonomi masyarakat dimulai dari Program Pengembangan Kawasan Ekonomi Masyarakat (KEM) pada tahun 2014.
Pada tahun tersebut, dilakukan pemasangan pipa sepanjang 2,5 km dari sumber mata air Gumantar untuk mengaliri lahan pertanian kelompok masyarakat. Air tersebut dimanfaatkan untuk mengairi berbagai jenis tanaman, seperti cabe keriting, jagung hibrida, jagung manis, sayuran, semangka, tomat; termasuk memelihara sapi, ayam potong, dan ikan air tawar. Scabra dan Setyowati (2019) menyatakan bahwa potensi yang minim pada suatu kawasan desa, harus dapat menjadi sumberdaya yang termanfaatkan dengan baik.

$$
\text { Akuaponik merupakan }
$$

perpaduan sistem budidaya antara hidroponik dengan akuakultur (budidaya ikan), sehingga menjadi suatu sistem produksi pangan terpadu (Sastro, 2015). Akuaponik menjadi sebuah model produksi pangan berkelanjutan yang menekankan pada konsep aliran nutrien. Sistem ini memadukan prinsip-prinsip ekologis berdasarkan pada level trofik organisme sehingga bersifat lebih alami dan sangat ramah lingkungan, menghasilkan produk organik karena bebas dari kontaminasi bahan kimia (seperti disinfektan, pestisida, dan antibiotik) (Sastro, 2016). Setyono dan Scabra (2019) menerapkan teknologi akuponik untuk meningkatkan hasil produksi ikan nila di Desa Kapu 
Kabupaten Lombok Utara dengan hasilnya cukup baik.

Sistem teknologi akuaponik pada awalnya muncul sebagai jawaban atas adanya permasalahan semakin sulitnya mendapatkan sumber air yang sesuai untuk budidaya ikan, khususnya di lahan yang sempit, Akuaponik yang merupakan salah satu teknologi hemat lahan dan air yang dapat dikombinasikan dengan berbagai tanaman sayuran. Aplikasi kombinasi akuaponik ini sesuai untuk pemanfaatan lahan sempit dan lahan kritis sehingga tetap produktif meskipun kondisi tanah kesuburannya rendah. Teknologi akuaponik ini dapat dikombinasikan dengan teknologi bioflok sehingga daya produksinya semakin berganda pada suatu tempat yang sama (Sulistyo et al., 2016).

\section{METODE KEGIATAN}

Kegiatan pengabdian ini akan dilaksanakan di Desa Gumantar Kecamatan Kayangan Kabupaten Lombok Barat, Nusa Tenggara Barat. Kegiatan pengabdian dilaksanakan dengan menyampaikan informasi kepada masyarakat tentang teknologi budidaya akuaponik, pelatihan budidaya sistem akuaponik, dan penanganan pasca panen.
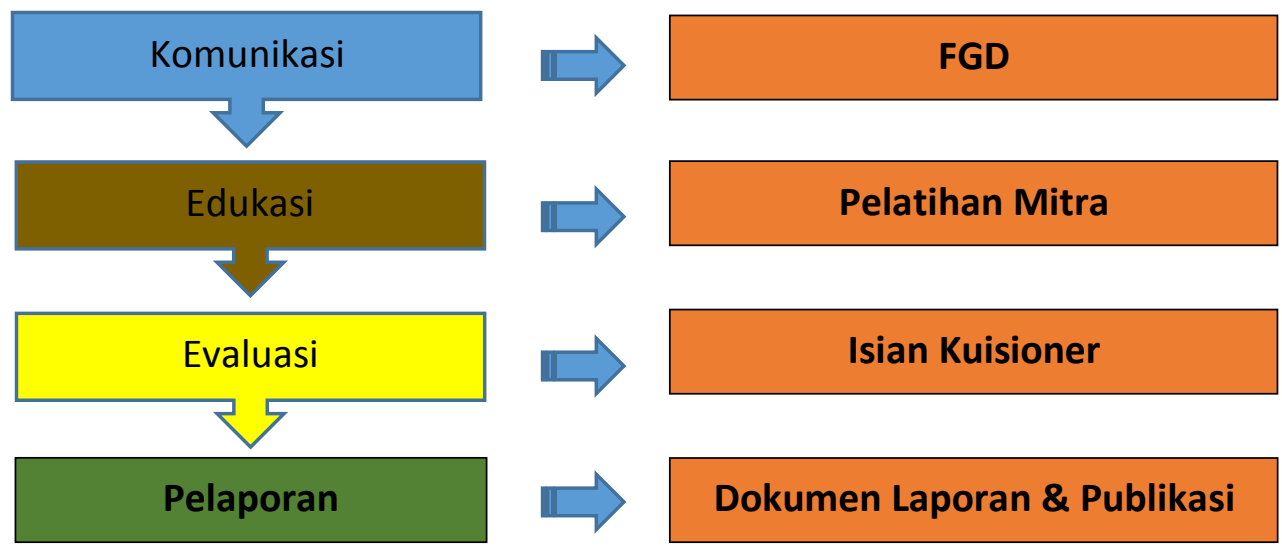

Gambar 1. Tahapan Kegiatan Pengabdian

Tahapan Kegiatan Pengabdian

Tahapan ke-1: Focus Group Discussion (FGD) dilakukan di mitra dengan cara mengumpulkan mitra untuk menentukan kebutuhan yang tepat. Luaran dari tahapan ini adalah data kebutuhan jumlah peserta pelatihan, waktu pelatihan dan durasi pelaksanaan pelatihan
Tahapan ke-2: Pelatihan. Setelah disetujui waktu dan tempat pelatihan, maka tahap berikutnya adalah pelaksanaan pelatihan. Pelatihan meliputi perancangan model/system budidaya akuaponik yang akan dilakukan, pelatihan pembuatan akuaponik system rakit apung, pelatihan pemeliharaan ikan 
lele yang baik (pemilihan bibit, pemberian pakan, penanganan penyakit, pemanenan), serta pelatihan budidaya tanaman sayuran. Tahapan ke-3: Evaluasi. Setelah pelaksanaan selesai, maka dilakukan evaluasi dengan cara mitra atau peserta pelatihan diminta mengisi kuesioner yang isinya untuk menilai ketepatan sasaran pada pelatihan dan pelaksanaan pengabdian ini secara keseluruhan.

Tahapan ke-4: Pelaporan. Akhir dari pelaksanaan adalah pembuatan laporan kegiatan, laporan penggunaan anggaran dan publikasi pada jurnal pengabdian.

\section{HASIL DAN PEMBAHASAN}

\section{Pelaksanaan FGD}

\section{Pelaksanaan}

kegiatan

pengabdian diawali dengan kegiatan focus group discussion (FGD) yang bertujuan untuk memperoleh masukan atau informasi mengenai permasalahan yang sifatnya lokal dan spesifik. FGD diikuti oleh 5 orang di rumah Bapak Eman pada tanggal 3 Agustus 2019. Hasil FGD tersebut antara lain: 1). Perlu dilakukan pemanfaatan lahan kering untuk kegiatan ekonomi masyarakat, khususnya budidaya perikanan; 2). Kegiatan budidaya perikanan yang akan dilakukan menggunakan sistem akuaponik; 3). Sistem akuaponik menggunakan metode NFT; 4). Lokasi kegiatan adalah di pekarangan rumah Bapak Eman.
Kegiatan budidaya perikanan yang dapat dilakukan pada lahan kering adalah menggunakan sistem akuaponik. Akuaponik merupakan sistem pertanian modern yang mengkombinasikan antara cara budidaya hidroponik dan akuakultur. Artinya, metode bercocok tanam tanpa tanah pada hidroponik digabungkan dengan teknik pemeliharaan ikan yang dikembangkan dengan teknik akuakultur. Dalam sistem akuaponik, ikan dan tanaman dipelihara bersama-sama dan akan bersimbiosis mutualisme (Bangkit et. al., 2017). Tanaman memperoleh media dan nutrisi dari air kolam dan limbah kotoran ikan, sedangkan ikan mendapat media hidup di air yang bersih setelah dibersihkan oleh tanaman. Limbah kotoran ikan banyak mengandung zat amoniak yang dapat diubah oleh cacing dan mikroba di sekitar akar tanaman menjadi zat lain. Zat lain inilah sebagai nutrisi yang amat dibutuhkan oleh tumbuhan. Selanjutnya air dialirkan kembali ke kolam ikan, namun sebelum masuk ke kolam ikan, air yang mengandung kotoran ikan disaring dan sisa-sisa kotoran ikan itu akan digunakan lagi untuk menutrisi tanaman.

Nutrient film technique (NFT) merupakan model budidaya hidroponik dengan meletakkan akar tanaman pada lapisan air yang dangkal. Air tersebut tersirkulasi dan 
mengandung nutrisi sesuai kebutuhan tanaman. Perakaran bisa berkembang di dalam larutan nutrisi, karena di sekeliling perakaran terdapat selapis larutan nutrisi.

\section{Pembuatan Kolam}

Persiapan kegiatan pengabdian dilakukan dengan membuat rancangan sistem NFT dan mempersiapkan alat serta bahan penunjang. Rancangan sistem NFT dibuat dengan mengedepankan efektifitas dan efisiensi pemanfaatan ruang, penggunaan tenaga dan biaya. Kolam dibuat menggunakan terpal dengan rangka kayu dan triplek. Penggunaan terpal didasarkan pada fleksibelitas bahan, murah, dan mudah untuk diaplikasikan. Rangka menggunakan kayu yang dibentuk persegi dan dilapisi triplek untuk mencegah kebocoran.

Sebelum melakukan pemasangan terpal pada rangka, terpal terlebih dahulu dilubangi dan dipasang sambungan $\mathrm{L}$ untuk membuat saluran pembuangan air dan pengatur ketinggian air. Alas terpal diisi menggunakan pasir halus dengan tujuan untuk mencegah kebocoran akibat bahan-bahan keras yang akan melubangi terpal. Ketinggian air diatur agar tidak melebihi ketinggian 1 meter, pengaturan ketinggian air berfungsi untuk mencegah meluapnya air pada saat hujan serta memberikan ruang yang cukup bagi ikan dan sinar matahari untuk masuk ke dalam kolam.

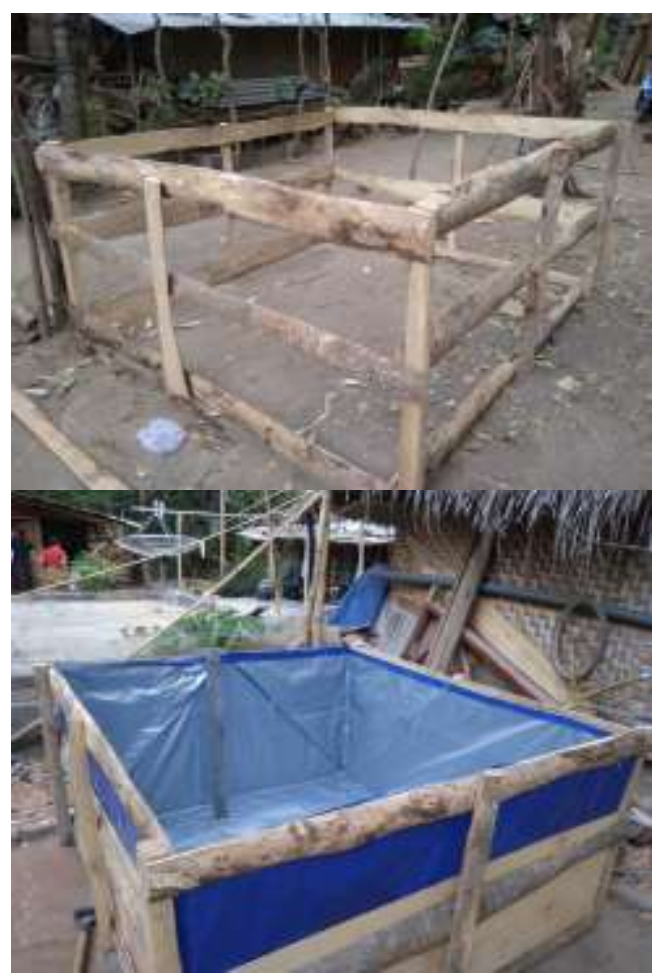

Gambar 2. Pembuatan Rangka dan Pemasangan Terpal

Perangkaian terpal dilakukan dengan hati-hati untuk mencegah terpal robek dan menghindari ikan terjebak di dalam lipatan terpal. Jenis terpal yang digunakan adalah A5 yang tergolong relatif tebal, terpal tersebut berukuran $4 \times 6$ meter.

\section{Pembuatan Pipa Hidroponik}

Pembuatan hidroponik dilakukan menggunakan pipa paralon 2,5 inchi dengan panjang masingmasing 4 meter. Masing-masing pipa dihubungkan satu sama lainnya menggunakan pipa $L$ dan $T$, sehingga terbentuk pipa berjumlah 6 lonjor. Masing-masing pipa tersebut 
selanjutnya dilubangi menggunakan bor yang telah dipasangi holesaw ukuran $44 \mathrm{~mm}$. Jarak antar lubang sekitar 10-15 cm, sehingga setiap lonjor pipa berjumlah sekitar 25 lubang. Langkah-langkah dalam melakukan pengeboran pipa yaitu:

1. Pasangkan holesaw ukuran $44 \mathrm{~mm}$ pada mata bor

2. Lakukan pengukuran titik yang akan dibor beserta jarak antar titik tersebut

3. Pengeboran dilakukan dengan tegak lurus, yaitu dengan menempelkan mata bor dengan titik yang sudah dibuat

4. Lakukan pengeboran menggunakan kedua tangan agar mata bor tidak berpindah dari titik yang telah ditentukan.

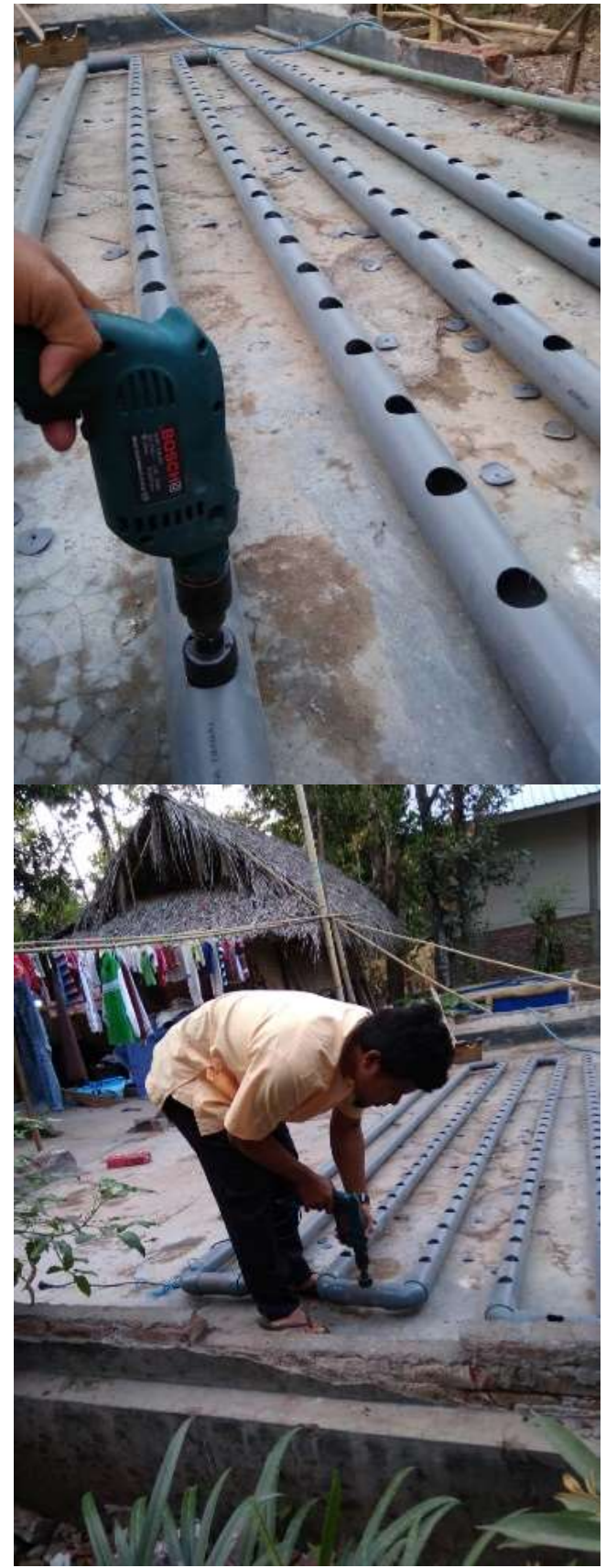

Gambar 3. Membuat Lubang pada Pipa

\section{Penyemaian Benih Sayuran}

Sayur yang digunakan dalam sistem akuaponik adalah selada hijau, green pakcoy, bayam merah, bayam hijau, kangkung, dan caisim manis. Penyemaian aneka jenis benih sayuran pada budidaya akuaponik 
diawali

dengan

mempersiapkan rockwool sebagai

media semai, wadah semai berupa tray plastik atau wadah lainnya yang bisa menampung air, dan benih sayuran yang ingin ditanam. Tahapan dalam melakukan penyemaian benih sayuran yaitu:

1. Rockwool dipotong dengan ukuran 2,5 2,5 cm atau $3 \times 3 \mathrm{~cm}$

2. Rockwool dibasahi dengan air bersih, yaitu dengan merendamnya sebentar atau menyiramnya dengan air bersih lalu ditiriskan

3. Rockwool yang sudah dibasahi diletakkan di wadah semai

4. Buat lubang kecil di bagian tengah rockwool atau di beberapa bagian permukaan rockwool menggunakan tusuk gigi. Kedalaman lubang tidak lebih dari 0,5 cm agar benih tidak sulit untuk tumbuh

5. Letakkan benih di setiap lubang rockwool menggunakan tusuk gigi

6. Setelah semua rockwool terisi benih, tutup wadah semai lalu letakkan di tempat yang terhindar dari sinar matahari. Tujuannya untuk menjaga kelembaban, sehingga benih mudah pecah dan berkecambah

7. Setelah sekitar 24 jam, benih bayam, kangkung dan pakcoi biasanya sudah berkecambah (sprout), sehingga sudah bisa dipindahkan ke lokasi yang terkena sinar matahari. Karena itu, agar benih yang sprout bisa langsung terkena sinar matahari, penyemaian dilakukan pada pagi hari. Tujuannya agar keesokan paginya, benih sudah pecah dan bisa dipindahkan ke lokasi yang terkena sinar matahari.

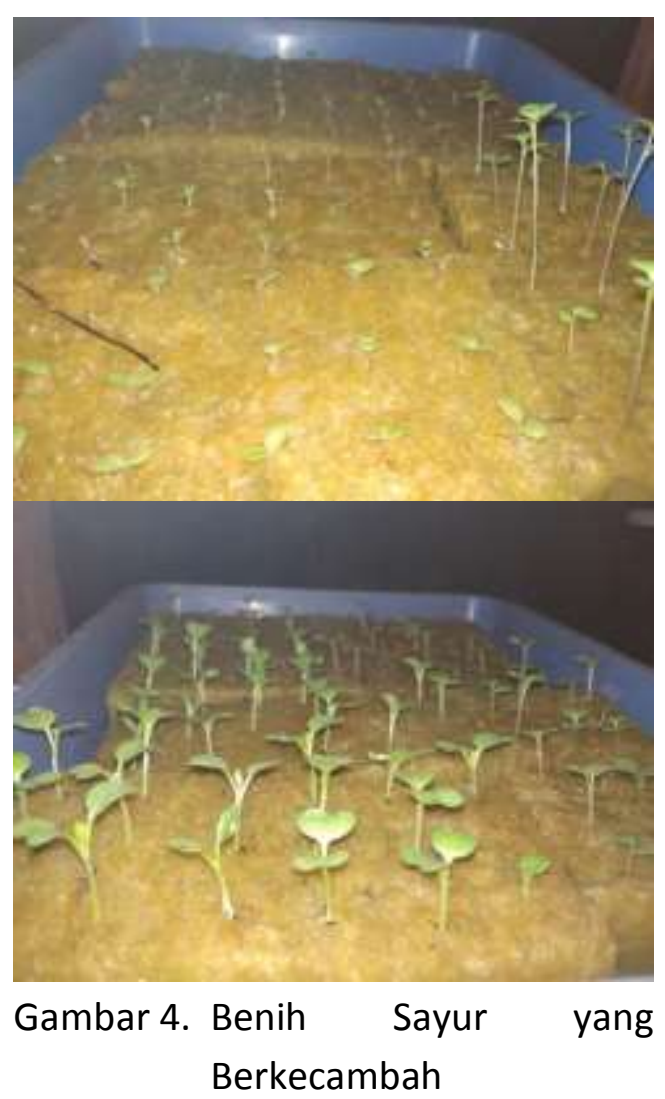

\section{Perangkaian Sistem Akuaponik}

Sistem akuaponik NFT pada prinsipnya adalah menggunakan pipa yang dirangkai sejajar dengan diatur titik terendahnya pada outlet, sehingga air yang dipompa dari dalam kolam bisa mengalir dengan baik dan bisa kembali lagi ke kolam. Yang harus diperhatikan dalam menggunakan sistem NFT adalah aliran air harus lancar agar air tidak 
meluap, selain itu untuk menjamin air agar dapat diserap oleh akar sayuran dapat menggunakan kain flanel yang diselipkan antara net pot dan rockwool.

Kegiatan pengabdian yang dilakukan yaitu masuk ke dalam musim panas, sehingga untuk mengurangi teriknya sinar matahari yang menyinari daun sayur dilakukan pengatapan menggunakan waring. Waring yang digunakan adalah berbahan plastik. Jika tidak dilakukan pengatapan menggunakan waring dikhawatirkan daun akan mudah layu.

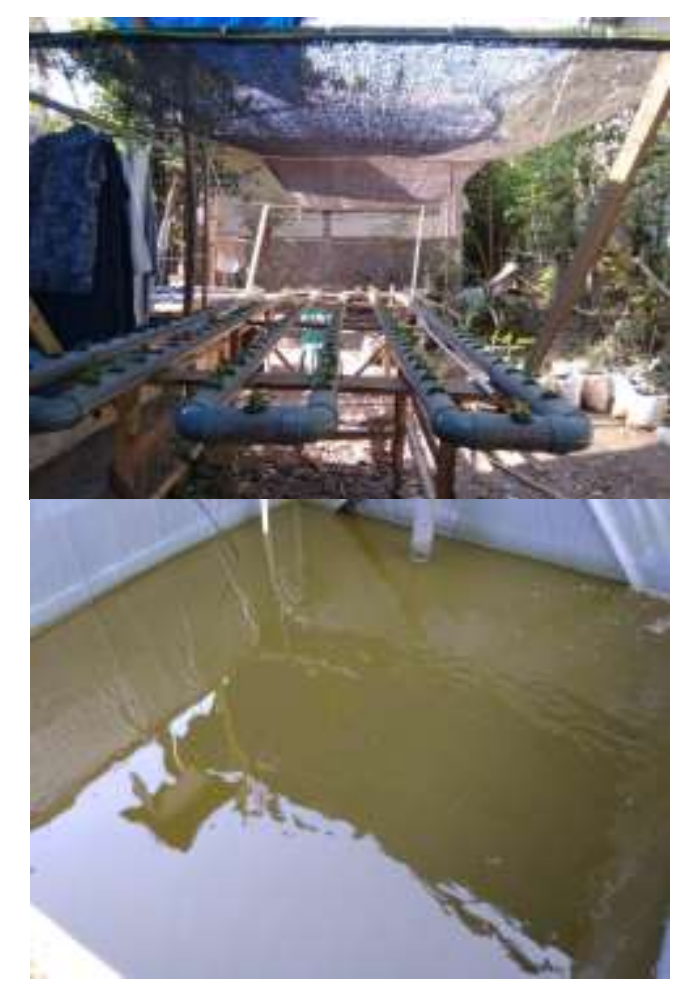

Gambar 5. Perangkaian

Sistem

\section{Pemeliharaan Sistem Akuaponik}

Sistem akuaponik yang telah dirangkai menggunakan 6 jenis tanaman sayur dan ikan lele sebagai biota penghasil limbah/feses. Benih ikan lele diperoleh dari Balai Benih Ikan (BBI) yang terletak di Batu Kumbung dengan ukuran 5-6 cm. Jumlah yang ditebar adalah 1.000 ekor. Penebaran benih lele awal dilakukan pada tanggal 1 September 2019 dengan level ketinggian air adalah $40 \mathrm{~cm}$. Jumlah daun sayur 3-4 helai dengan lebar daun 1-1,5 cm. Keterangan lebih lengkap dapat dilihat pada Tabel 1. 
Tabel 1. Pertumbuhan Sayur dan Ikan Lele pada Sistem Akuaponik

\begin{tabular}{|c|c|c|}
\hline No. & Tanggal & Keterangan \\
\hline 1 & 1 September 2019 & Jumlah daun 3-4 helai, lebar daun 1-1,5 cm \\
\hline 2 & 8 September 2019 & Benih lele panjang $7-10 \mathrm{~cm}$, lebar daun $1,5-2 \mathrm{~cm}$ \\
\hline 3 & 12 September 2019 & $\begin{array}{l}\text { Benih lele mati } 136 \text { ekor akibat terjebak dalam } \\
\text { plastik }\end{array}$ \\
\hline 4 & 15 september 2019 & $\begin{array}{l}\text { Panjang benih lele } 9-11 \mathrm{~cm} \text {, lebar daun sayur 1,5-3 } \\
\mathrm{cm}\end{array}$ \\
\hline 5 & 22 September 2019 & $\begin{array}{l}\text { Panjang benih lele } 10-12 \mathrm{~cm} \text {, lebar daun sayur 2-4 } \\
\mathrm{cm}\end{array}$ \\
\hline 6 & 29 September 2019 & $\begin{array}{l}\text { Panjang benih lele } 13-14 \mathrm{~cm} \text {, lebar daun sayur 2-6 } \\
\mathrm{cm}\end{array}$ \\
\hline 7 & 6 Oktober 2019 & $\begin{array}{l}\text { Panjang benih lele } 14-16 \mathrm{~cm} \text {, lebar daun sayur } 2-8 \\
\mathrm{~cm}\end{array}$ \\
\hline 8 & 13 Oktober 2019 & $\begin{array}{l}\text { Panjang benih lele } 15-18 \mathrm{~cm} \text {, daun sayur } \\
\text { mengalami kelayuan karena intensitas cahaya } \\
\text { matahari terlalu tinggi }\end{array}$ \\
\hline 9 & 20 Oktober 2019 & Panjang benih lele $16-20 \mathrm{~cm}$, daun sayur layu \\
\hline 10 & 27 Oktober 2019 & $\begin{array}{l}\text { Panjang benih lele } 21-22 \mathrm{~cm} \text {, beberapa tanaman } \\
\text { sayur mengalami kematian }\end{array}$ \\
\hline 11 & 3 Nopember 2019 & $\begin{array}{l}\text { Panjang benih lele } 21-25 \mathrm{~cm} \text {, sebagian besar } \\
\text { tanaman sayur mengalami kematian }\end{array}$ \\
\hline
\end{tabular}

Akibat cuaca yang terlalu panas karena intensitas matahari yang terlalu tinggi menyebabkan sebagian sayur mengalami kelayuan hingga kematian. Kelayuan daun sayur dimulai pada tanggal 13 Oktober 2019, hingga mengalami kematian pada tanggal 27 Oktober 2019. Benih lele yang dipelihara ditemukan mengalami kematian pada tanggal 12 September 2019 dikarenakan terjebak di dalam sampah plastik yang masuk ke dalam kolam. Hingga pada tanggal 3 Nopember 2019 panjang ikan lele yang dipelihara mencapai ukuran 21-25 cm. Berdasarkan hasil pengukuran sampel, terdapat variasi pertumbuhan ikan lele. Hal tersebut diduga karena tidak dilakukannya grading selama pemeliharaan, sehingga ikan yang memiliki pertumbuhan cepat mendominasi di dalam kolam. Ikan lele yang berukuran kecil diduga kalah dalam persaingan memperoleh pakan dan ruang. 


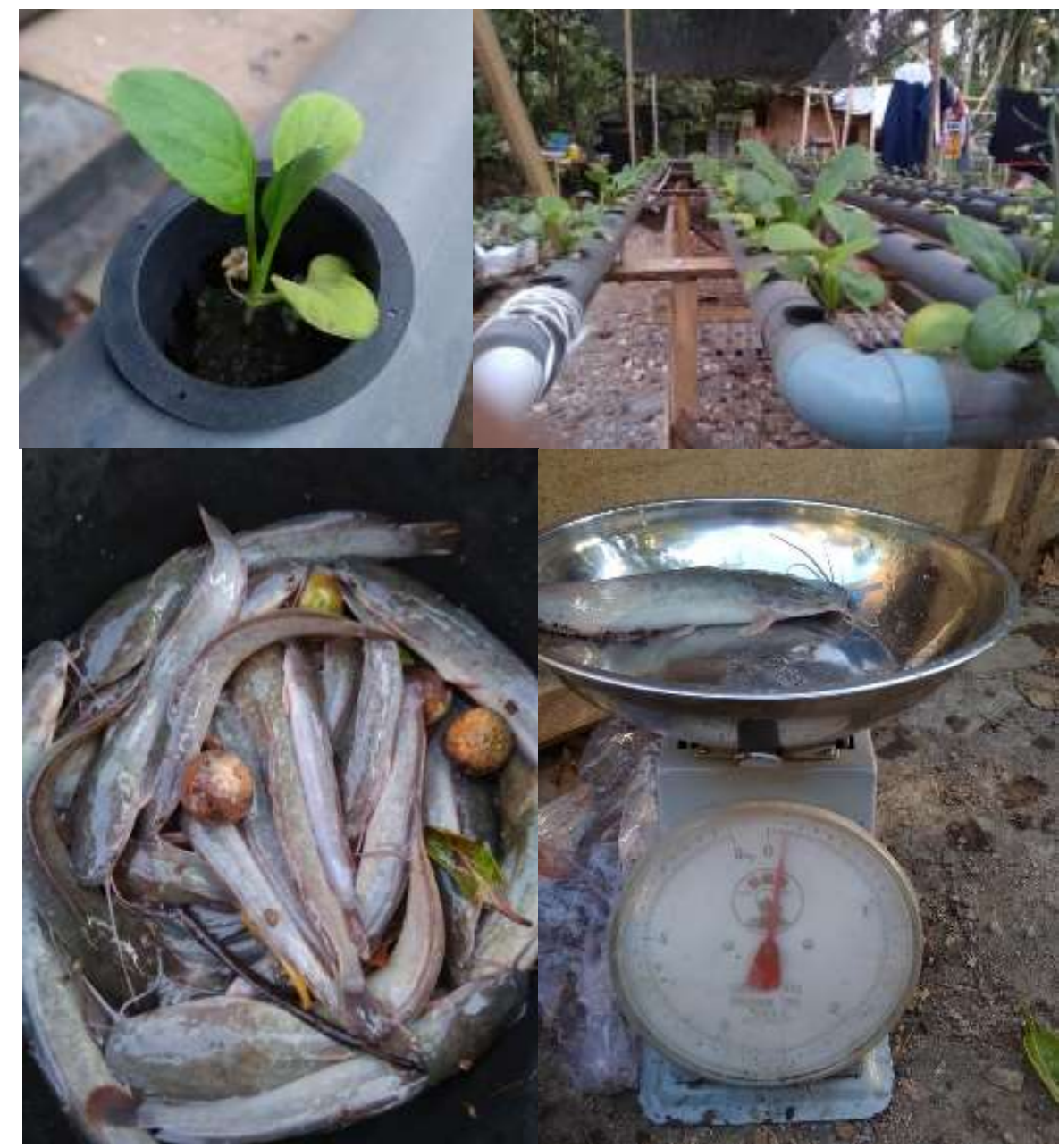

Gambar 6. Pertumbuhan Sayur dan Ikan Lele

\section{UCAPAN TERIMA KASIH}

Terima kasih disampaikan kepada Kemristekdikti atas hibah PNBP Tahun 2019 yang diberikan kepada kelompok pengabdian kepada masyarakat dengan judul Peningkatan Produktivitas Lahan Kering Melalui Budidaya Ikan Sistem Akuaponik, sehingga kegiatan ini bisa terlaksana dengan baik.

\section{DAFTAR PUSTAKA}

Bangkit I, Sugandhy R, Indriani PD. 2017. Aplikasi Budidaya Ikan Integratif dengan Sistem Akuaponik dalam Pemanfaatan Pelataran Rumah sebagai Upaya Peningkatan Pendapatan Masyarakat di RW 05 Desa Sayang, Jatinangor-Sumedang. Jurnal Pengabdian Kepada Masyarakat ISSN 1410 - 5675. Vol. 1, No. 3, Juni 2017: 145 149.

Sastro Y. 2015. Akuaponik: Budidaya Tanaman Terintegrasi dengan Ikan, Permasalahan Keharaan 
dan Strategi Mengatasinya. Buletin Pertanian Perkotaan Volume 5 Nomor 1.

Sastro Y. 2016. Teknologi Akuaponik Mendukung Pengembangan Urban Farming. Edisi Pertama, 102 hal. Balai Pengkajian Teknologi Pertanian (BPTP) Jakarta. Jakarta.

Scabra AR, Budiardi T, Setiyanto DD. 2016. Kinerja produksi ikan sidat (Anguilla bicolor) berukuran 10 gram dengan pemberian kalsium karbonat (CaCO3) pada media budidaya. Jurnal Akuakultur Indonesia, Vol. 15 No. 1.

Scabra AR, Setyowati DN. 2019. Peningkatan mutu kualitas air untuk pembudidaya ikan air tawar di Desa Gegerung
Kabupaten Lombok Barat. Jurnal Abdi insani Volume 6, Nomor 2.

Setyono BDH, Scabra AR. 2019. Teknologi Akuaponik Apung Terintegrasi Budidaya Ikan Nila Di Desa Kapu Kabupaten Lombok Utara. Jurnal Abdi insani Volume 6, Nomor 2.

Sulistyo MAB, Taufikkurrahman, Noeriati D. 2016. Teknologi Akuaponik Untuk Memperkuat Ekonomi Warga RW 10 Kelurahan Bandungrejosari Kota Malang. Prosiding Seminar Nasional dan Gelar Produk (SenasPro) di Universitas Muhammadiyah Malang Tanggal 17-18 Oktober 2016. Hal: 99-109. 